\title{
Exploration and Practice of Higher Vocational Curriculum Reform Based on Network Learning Space
}

\author{
Wuxue Jiang ${ }^{1, a}$, Guangzai Ye ${ }^{1, b}$, Bin $\mathrm{Xie}^{2, \mathrm{c}}$, Cao Chai ${ }^{2, \mathrm{~d}}$ \\ ${ }^{1}$ Department of Computer Engineering, Dongguan Polytechnic, Dongguan 523808, China. \\ ${ }^{2}$ Division of teaching affairs, Dongguan Polytechnic, Dongguan 523808, China \\ ajiangwx@dgpt.edu.cn, bYegz@dgpt.edu.cn, c871403792@qq.com, d401174996@qq.com
}

\begin{abstract}
With the development of network technology, the construction level of network learning space is getting higher, which is complementary to the traditional education modes to a certain extent. This paper takes higher vocational colleges as the research objects, aims at the characteristics of higher vocational education, integrates the advantages of resources, resource presentation forms and interaction modes in network learning space, analyzes every area of changes between teaching and learning under the support of network learning space, proposes new modes of higher vocational teaching and learning based on online learning space, and points out the problems that should be paid attention to when using the network learning space.
\end{abstract}

Keywords: online learning space; higher vocational curriculum; curriculum reform.

\section{Current Situation and Problems of Higher Vocational Education}

(1) Main ways of higher vocational education

In recent years, as the level of higher vocational education improves, some colleges have made active innovation, and form "double-qualified teaching mode, virtual reality teaching mode, and optional class teaching" and so on. However, most of the teaching modes of higher vocational education have obvious limitations at present, although classrooms and schools provide students with rich teaching resources, they also limit the learning space of students. The limited on-campus teaching time makes it impossible for some students with higher learning demands to get the ideal resource support outside the classroom. On the other hand, in the traditional classroom teaching, teachers' professional quality and teaching ability has become the "double-edged sword" that affects students. While giving students professional guidance, it may also affect the students' development due to teachers' inadequate ability.

(2) Students' learning characteristics in vocational colleges

Vocational colleges are educational institutions which take practical talent training as the direction, due to the influence of teaching objectives, students in vocational colleges tend to pay more attention to practical operational ability, emphasize the application of knowledge, rather than understanding and innovation of knowledge. This makes the students in vocational colleges lack the attention of professional knowledge, and puts most of their energy into the mastery of professional skills. Although this method meets the needs of "practical talents", it also affects the formation of students' "comprehensive quality" to a certain extent, it is difficult to have innovative ability and the improvement space for professional level is not enough. Moreover, due to the influence of China's examination into higher school, students in vocational colleges often have "weak basic knowledge, insufficient understanding ability", low interest in learning, lack of self-discipline management" and so on. This makes it difficult for students in vocational colleges to study independently and learning persistence is relatively poor. In particular, there are obvious defects in the understanding of theoretical knowledge. Considering the students' learning characteristics in vocational colleges, the professional and scientific teaching guidance has more important significance. 


\section{Characteristics of Network Learning Space}

(1) Extensiveness of resources

The online learning space is an open education space based on the Internet, which not only provides rich educational and teaching resources for any user, but also its educational source is completely open. In the online learning space, the limitation between schools and regions will be completely broken. Teachers and other educators can upload their own educational resources through the online learning space to achieve resource sharing. Therefore, the network learning space has obvious characteristics with extensive resources, under the support of convenient operation and low cost, the network learning space can reserve rich educational and teaching resources, thus providing students with selective learning and enriching students' knowledge sources, moreover, it also compensates for the problem of teachers' inadequate ability.

(2) Immediacy of application

Unlike traditional classroom teaching and campus teaching, the online learning space has obvious immediacy. It completely breaks the time and location limitations of traditional teaching. Students can open online learning spaces anytime, anywhere, learn relevant knowledge, and get guidance from teachers online. Therefore, the immediacy of application is the fundamental reason why the network learning space can be quickly concerned by a large number of students; it also makes the network learning space have strong integration ability and can be effectively integrated with any educational model and education level in a more diversified form.

(3) Interactivity of information

The network learning space is different from the traditional books, and the data communication technology makes the network learning space have information interaction ability. It not only can replace the teacher-student interaction in traditional classroom teaching to a certain extent, but also enrich the interaction among students, even the interaction among students and enterprises, and the interaction between teachers and enterprises. The interactivity of information makes the network learning space have the strong resources integration ability, and can reflect the most realistic learning situation, the most up-to-date professional knowledge, in addition to big data statistics and analysis functions, it can help teachers and students to carry out scientific learning management and improve the quality and efficiency of learning.

\section{Teaching Modes based on Network Learning Space}

(1) Output-oriented teaching mode

The output-oriented method is a new teaching mode proposed by Professor Wen Qiufang and his team in 2014, which is based on "output-driven, input-prompted" basic logic and covers three links: drive, facilitation and evaluation. In higher vocational colleges, and students lack independent thinking, which is an important factor affecting learning efficiency; and it is also the main reason why students cannot form good innovative ability. Therefore, the network learning space can be utilized to construct a production-oriented teaching mode.

\subsection{Set Goals and Learn Independently}

Before the teachers conduct professional teaching, the teacher can pre-set the learning objectives according to contents of professional courses, and propose corresponding professional questions as the "driver" content. According to the "driver" provided by the teachers, the students conduct selfexploration learning through the online learning space, retrieve the corresponding knowledge points, answer the questions proposed by the teachers and complete the self-study goal. In this process, the online learning space will bear teachers' educational function, when setting the questions and learning objectives, the teachers should also fully refer to the resources in the online learning space and ensure that the students can find the corresponding knowledge contents through the network. In vocational colleges where students' learning ability is weak, teachers can directly assign network resources and require students to learn independently. Through the early "drive" learning earlier stage, students will 
have questions, and then guide students to carry out subsequent classroom learning with problems and achieve targeted learning.

\subsection{Information Interaction and Resource Sharing}

In the "facilitation" stage, teachers can adopt the teaching mode of information interaction and resource sharing. The resources of online learning space and book contents are used; students are required to carry out "semi-autonomous exploration" learning in combination with the problems they have formed in the "drive" process. In this process, the learning resources given by teachers should have certain guidance and can give students some inspiration. Moreover, teachers also need to cooperate with a certain degree of explanation to improve students' understanding for learning resources. In order to better realize the teaching effect and open up the students' thinking, the students can also use the online learning space after class, teachers provide students with resource sharing space. Through the platform, personal learning experiences are shared as references for students.

\subsection{Teachers' Evaluation and System Assessment}

In the "evaluation" phase, the online learning space plays the role of assessor. On the one hand, teachers need to integrate the classroom teaching situation to make a subjective evaluation of students' learning process, including students' learning attitude, students' learning efficiency, and students' learning quality, on the other hand, the online learning space is used to conduct test question assessment for students. Through online learning space, students can complete the corresponding test question assessment according to teachers' requirements, and the system automatically generates test question review result and error analysis and helps students to learn independently, so that high vocational students can still independently analyze and interpret the questions without the tutors' guidance. Moreover, the tutor can also count the students' answer condition through the online learning space, and use the data analysis function of the online learning space to analyze the students' common problems and common mistakes, and then guide the teachers carry out remedial teaching.

(2) Students' advance and diversion mode

The Traditional vocational college teaching is balanced teaching oriented by "average level", whether the distribution of teaching resources, or the progress and depth of teaching, the "equal opportunities and moderate difficulty" principle is pursued. However, in the actual teaching, the students themselves have obvious differences, and their demands for teaching are also different. However, the teaching space in the school has certain limitations, due to the limitations of teachers' resources, it is often impossible to achieve complete differentiated teaching. Against this background, the online learning space can be used to construct students' advance and diversion learning mode.

The "advance" of students means that the students determine the learning process through check or evaluation, and then carry out different levels of advanced study according to the learning process. The "diversion" of students is to conduct development orientation according to the learning ability and personal intention, students are diverted to different professional positions, and then they can carry out professional learning according to the job requirements purposefully in the subsequent learning.

In order to realize the advance and diversion teaching mode, the network learning space needs to be used as a continuation and assessment platform for on-campus teaching. On the one hand, teachers and colleges provide different depths of teaching resources (including teaching videos, internship positions, enterprise visits, study tours and practical training, etc.) in the online learning space, students can obtain access rights according to different levels after passing the assessment, on the other hand, vocational colleges should set up a "post diversion" system in the online learning platform according to the major settings, and give them scientific and reasonable development suggestions in the form of "career guidance" in accordance with students' assessment condition.

It is noteworthy that the "advance and diversion" mode based on the network learning space is not at the cost of "sacrifice some students' fair learning opportunities". Only as a continuation of college education, the online learning space provides better education services for better talents. Therefore, in the "advance and diversion" mode, the network learning space is more market-oriented and requires 
double selection between students and platforms. On-campus education still maintains the original "equal opportunity for all" mechanism and ensures that every student can get fair teaching resources.

(3) Use data statistics to improve teaching evaluation level

Information technology is one of the important features of the network learning space; the network learning space supported by modern information technology often has rich big data analysis ability. But in traditional vocational colleges, the proportion of manual assessment is relatively high; teachers' energy is limited, and do not have the ability to handle big data. Therefore, data statistics in the network learning space can be used to improve teaching evaluation level.

\subsection{Record Students' Growth Process}

The network learning space has data storage function. Therefore, vocational colleges can graft all kinds of assessments into the network learning space, and use their huge data storage function to record the fluctuation condition of students' results, thus helping teachers to better analyze student learning condition, and set the teaching plan according to the actual learning situation.

\subsection{Evaluate Knowledge Loopholes}

The data statistics function of network learning space is used; the teacher can conduct statistical analysis on the students' learning condition, thereby discovering the general problems existing in the staged teaching, and then carry out remedial teaching for the knowledge points with poor learning effect in the subsequent teaching. Moreover, students can consolidate and summarize after class, as long as they encounter problems in the learning process, they can enter the "online answering room" module of the online learning space to ask questions at any time, moreover, students can give advice on the whole teaching of teachers in the online teaching space and give true and sincere evaluation and feed back to the teacher.

\section{Problems that should be Paid Attention to When Using Network Learning Space}

(1) Cohesion problem of teaching

The online learning space is different from vocational colleges, because it has the openness of resources and is an informal educational institution; it often has obvious confusion in contents. Moreover, due to the differences in the design of professional courses in different places, the online learning space is often difficult to take into account the large differences in different urban areas, and cannot fully match the vocational colleges. Therefore, when using the network learning space, we should pay attention to cohesion problem of teaching. Teachers should pre-arrange the learning resources in the network space; ensure that the online learning space provided for students has relevant resources that are consistent with their learning contents and learning difficulty. Moreover, if conditions permit, higher vocational colleges can establish online learning platform for the college through resource integration and independent creation, and then make it as the continuation of oncampus teaching. So, ensure that the cohesion problem of teaching will not occur.

(2) Students' usage rate problem

The student's usage rate is the condition where students use the online learning space according to the teachers' guidance. Due to higher supervision difficulty in of network learning space, teachers often cannot regularly supervise students' use condition. Therefore, the use of network learning space should pay attention to the student's usage rate; it is necessary to ensure that students can use the online learning space correctly and normatively through the scientific and reasonable supervision mechanism, thus avoiding the interruption of learning. In order to better realize the supervision of learning and avoid the difficulties of network supervision, teachers can use the classroom evaluation method to examine the students' use condition, namely the teachers investigate students' learning condition in the classroom according to learning contents of online learning space, and urges students to use the network learning space as required in the disguised form to improve the usage rate of network space. 
(3) Rationality problem of learning time

As the continuity platform of professional education in vocational colleges, online learning space necessarily needs to use time outside normal teaching, namely taking up students' rest time, while students' learning energy is limited, and students' learning enthusiasm in vocational colleges is limited. Therefore, the use of network learning space should pay attention to the rationality problem of learning time. Do not over-occupy students' spare time and avoid the problem of insufficient energy in school. Teachers should reasonably arrange the use intensity of network learning space, and always maintain the "school education as the principal thing and supplemented by network learning space" educational principle.

\section{Summary}

The application of online learning space is one of the important ways of "Internet + education", with the improvement of information technology in our country and the development of online education, the combination of vocational education and online learning space will become an inevitable trend. In the application of online learning space, it is necessary to attach more importance to the complementarity of online educational resources and college educational resources, the openness, interaction, immediacy and extensiveness of the online learning platform are made full use of, etc., and realize the reform of vocational education.

\section{Acknowledgements}

This work was financially supported by the Guangdong education science 13th five-year plan project (No.2018GXJK293,2018GXJK394), and support by the Teaching achievement cultivation project of Dongguan Polytechnic (CGPY201801, CGPY201802, CGPY201803), and support by Guangdong teaching reform research and practice project (GDJG2019003, GDJG2019004).

\section{References}

[1]. Van Leeuwen, Anouschka. Teachers' perceptions of the usability of learning analytics reports in a flipped university course: when and how does information become actionable knowledge? ETR\&D-EDUCATIONAL TECHNOLOGY RESEARCH AND DEVELOPMENT. Vol. 67(2019), p. 1043-1064.

[2]. Jiang Wuxue, Bao Jingjing, Gao Libin, et al. Situational Reconstruction of C Programming Technology based on the Systematic Work Process for polytechnic. 6th International Conference on Applied Science, Engineering and Technology (ICASET). Qingdao, MAY 29-30, 2016, p. 397-402.

[3]. McGrew Sarah, Smith Mark, Breakstone Joel, et al. Improving university students' web savvy: An intervention study. BRITISH JOURNAL OF EDUCATIONAL PSYCHOLOGY. Vol. 89(2019), No. 3, p. 485-500.

[4]. Vanegas Yenny Alejandra Moreno, Vishnu Prakash. Management of Helicobacter pylori in Patients with Immune Thrombocytopenia. ADVANCES IN PHYSIOLOGY EDUCATION. Vol. 43(2019), No. 3, p. 259-265.

[5]. Jiang Wuxue, Chai Pei, Chen Yuqiang, et al. University-enterprise Cooperation Practical Teaching Evaluation Model for polytechnic based on AHP and Fuzzy. International Conference on Computational Science and Engineering (ICCSE). Shandong, JULY 20-21, 2015, p. 282-285.

[6]. Dirks-Naylor Arnie J., Cook Corbin, Nhean Pov. Development and assessment of an academic performance enrichment program for low-performing, first-year pharmacy students. ADVANCES IN PHYSIOLOGY EDUCATION. Vol. 43(2019), No.3, p. 259-265. 